\title{
Measured and Parameterized Energy Fluxes Estimated for Atlantic Transects of R/V Polarstern
}

\author{
KARL BUMKE AND MichaEl SCHLUNDT \\ GEOMAR Helmholtz Centre for Ocean Research Kiel, Kiel, Germany \\ JOHN KALISCH \\ Institute of Physics, Carl von Ossietzky University Oldenburg, Oldenburg, Germany \\ ANDREAS MACKE \\ Leibniz Institute for Tropospheric Research (TROPOS), Leipzig, Germany \\ HENRY KLETA \\ German Weather Service Hamburg Branch Office (DWD), Hamburg, Germany
}

(Manuscript received 2 July 2013, in final form 25 October 2013)

\begin{abstract}
Sensible and latent heat fluxes were estimated from turbulence measurements gathered during several Atlantic Ocean transects of the research vessel (R/V) Polarstern. The inertial dissipation method was used to analyze the data. Resulting bulk transfer coefficients were then applied to the data from the ship's meteorological system to get continuous time series of the heat fluxes. Combined with the measured downward solar and longwave radiation fluxes it allows for an estimate of the total energy budget at the air-sea interface. Comparing these parameterized energy fluxes to those based on the Coupled Ocean-Atmosphere Response Experiment, version 3 (COARE3.0), bulk flux algorithm shows very strong agreement.
\end{abstract}

\section{Introduction}

The world's oceans contain the bulk of all freely available water on our planet with considerable spatial and temporal salinity variations. To a large extent the surface salinity variations are caused by the geographically varying freshwater fluxes, which are generated by the difference between precipitation and evaporation at the ocean's surface.

However, even to date, the uncertainties of net freshwater flux into the oceans are difficult to assess. The relative paucity of evaporation observations and the uncertainties of currently employed empirical approaches lead to large uncertainties of evaporation products over the ocean (Schmitt 1999; Large and Yeager 2009). Because evaporation measurements are hardly available

Corresponding author address: Karl Bumke, GEOMAR HelmholtzZentrum für Ozeanforschung Kiel, FB1/ME, Düsternbrooker Weg 20, 24105 Kiel, Germany.

E-mail:kbumke@geomar.de over the oceans, ground truth values of evaporation are usually derived from meteorological standard parameters via a bulk parameterization, making use, for example, of the Coupled Ocean-Atmosphere Response Experiment, version 3 (COARE3.0), bulk flux algorithm (Fairall et al. 2003). Doing so, a study from the Objectively Analyzed Air-Sea Fluxes (OAFlux) project (Yu et al. 2008) showed that several global datasets based on synoptic observations or reanalysis data differ from evaporation rates estimated from buoy data by up to $20 \%$. Muraleedharan and Pankajakehan (2008) concluded from a validation study of satellite-derived latent heat fluxes that more in situ observations are needed.

Ocean currents are also, in part, driven by the exchange of energy due to radiation fluxes. As for turbulent heat fluxes, there is still a shortage of available radiation flux measurements over the ocean (e.g., Rutledge et al. 2006), while over land, for example, the Baseline Surface Radiation Network (BSRN; Ohmura et al. 1998) provides accurate measurements. 
TABLE 1. Cruise legs of the R/V Polarstern and their expedition reports.

\begin{tabular}{lcl}
\hline \hline \multicolumn{1}{c}{ Cruise leg } & \multicolumn{1}{c}{ Date } & Expedition report \\
\hline ANT-XXIV/4 & 18 Apr-20 May 2008 & Macke (2009) \\
ANT-XXV/5 & 11 Apr-24 May 2009 & $\begin{array}{c}\text { Zenk and El Naggar } \\
(2010)\end{array}$ \\
ANT-XXVI/1 & 16 Oct-25 Nov 2009 & $\begin{array}{c}\text { El Naggar and Macke } \\
(2010)\end{array}$ \\
ANT-XXVII/1 & 25 Oct-26 Nov 2010 & Bumke (2011) \\
\hline
\end{tabular}

Within the frame of OCEANET (autonomous measurement platforms for energy and material exchange between ocean and atmosphere; Macke et al. 2010), we have performed both radiation flux and heat flux measurements on Atlantic transects (Table 1) on board the research vessel $(\mathrm{R} / \mathrm{V})$ Polarstern during the recent years.

\section{Data and methods}

\section{a. Radiation}

Radiation measurements were performed using a Kipp \& Zonen CMP 21 radiometer for global radiation $F_{\text {sw }}$ and a CGR 4 for the downward longwave radiation $F_{\mathrm{lw}}$. Both instruments were mounted on the OCEANET container placed on the ship's monkey island. Global radiation data are available from the ship's meteorological system as well (El Naggar and Fahrbach 2010). A comparison shows that these global radiation measurements $F_{\text {swship }}$ agree well with the OCEANET measurements $F_{\text {SwOCEANET }}$, having a correlation coefficient of 0.984 and a negative bias of $3.9 \mathrm{~W} \mathrm{~m}^{-2}$. Taking the uncertainties of both measurements into account, a regression equation can be written as follows:

$$
F_{\text {swship }}=0.976 F_{\text {swOCEANET }}+0.75 \mathrm{~W} \mathrm{~m}^{-2} \text {. }
$$

Similar results were shown in a detailed investigation of shortwave and longwave budgets at the sea surface based on measurements on board the R/V Polarstern (Kalisch and Macke 2012).

Reflected solar radiation was computed according to Taylor et al. (1996), where upward longwave radiation $F_{\mathrm{lw}}^{\uparrow}$ is computed according to the Stefan-Boltzmann law:

$$
F_{\mathrm{lw}}^{\uparrow}=0.97 \sigma T_{s}^{4},
$$

where $\sigma$ is the Boltzmann constant and $T_{s}$ is the sea surface temperature, assuming an emissivity of 0.97 for the sea surface.

\section{b. Heat flux measurements}

The basic measurements are inertial dissipation (ID) flux estimates and bulk variables. Turbulence measurements were made using a sonic anemometer and an infrared hygrometer, both mounted on the crow's nest approximately $32 \mathrm{~m}$ above the sea surface. The sonic anemometer, type USA-1, manufactured by METEK, Pinneberg, Germany, sampled at a rate of $30 \mathrm{~Hz}$. The absorption hygrometer, type M100, manufactured by Analytical Application, Boulder, Colorado, sampled at a rate of $10 \mathrm{~Hz}$. The hygrometer was mounted alongside the sonic anemometer as close as possible, taking flow distortion into account. The raw data of the three wind components, sonic temperature, and absolute humidity were stored. At a lower sample rate of $5 \mathrm{~Hz}$, roll and pitch angles, measured by a system of oil damped pendulums, were recorded to quantify the ship's motions due to waves and swell. Using this information, a coordinate transformation was applied to the wind measurements to convert to longitudinal and lateral wind components. Meteorological sensors to measure bulk variables were those of the ship's operational measurement system, composed of air pressure, air temperature, humidity, intake temperature, and wind speed and direction. The ship's measurements were taken on the crow's nest at a height of about $32 \mathrm{~m}$ (temperature and humidity) and on a crossbar on a mast above the radar platform at a height of about $39 \mathrm{~m}$. The intake temperature was obtained at a depth of $5 \mathrm{~m}$. The skin temperature itself was not measured. Therefore, it was computed following Hasse (1970) from the intake temperature, taking into account measured radiation fluxes and heat fluxes. Since the upward longwave radiation depends on the skin temperature itself, it is computed iteratively until convergence in the skin temperature was reached. The scheme to derive the skin temperature from the intake temperature is simpler than that used in the COARE3.0 bulk flux algorithm (Fairall et al. 2003) with respect to the warm layer, which is built up during the daytime by insolation. This had been done because measurements of local insolation on a moving ship for preceding hours are unknown.

Humidity at the sea surface was estimated from the skin temperature taking into account the $2 \%$ reduction of the vapor pressure of water due to salinity. Ship speed and course were provided by a Doppler log and a gyrocompass with the ship's position given by GPS.

Raw data of the turbulence measurement system were checked for outliers and missing data, which are mainly caused by sea spray and rain drops. A maximum of 100 erroneous values are allowed in each time series, which have a total length of about 54000 data points for wind and temperature and about 18000 data points for humidity. Missing data were replaced by the mean value of the corresponding time series. 
To avoid flow distortion from the instruments mounted on the same crossbar and to minimize the flow distortion from the ship's superstructure, only data where the relative wind direction was within a range of $\pm 60^{\circ}$ of the bow were used. Little is known about the flow distortion. Berry et al. (2001) focused on flow distortion at the lattice mast only for wind coming directly over the bow. Their Fig. A1 shows the deceleration/acceleration of a flow along the ship's axis. Therefore, it can be concluded that the positions of both the ship's anemometers and the turbulence measurement system are only slightly influenced by flow distortion. For measurement heights above $30 \mathrm{~m}$, vertical displacement plays a minor role.

\section{c. Flux-processing method}

In this study, we use the so-called ID method. Besides the direct eddy correlation method, the ID technique represents an approach to derive turbulent flux estimates (e.g., Fairall and Larsen 1986), utilizing characteristics of the inertial subrange of atmospheric velocity and turbulence spectra. Its application has several advantages compared to the direct eddy correlation method; to name but one, it is rather insensitive to the sensors' acceleration caused by the ship's motions due to waves. Thus, using the ID technique, there is no need to measure these accelerations, which keeps the measurement system simpler. However, the ID technique requires a number of assumptions to be made (e.g., Edson et al. 1991). In general it allows only the derivation of the magnitude of fluxes; their sign has to be taken from measurements of the bulk variables. Further, the validity, for example, of the Monin-Obukhov similarity theory is required, as it is for all bulk algorithms (Grachev et al. 2011). This implies that the ID technique predicts only the downstream component of the wind stress or turbulent shear stress due to the assumption that wind and stress vectors, and not the wave-induced stress, are aligned in the same direction. As a consequence, the method fails under conditions of light winds in the presence of swell; especially when the swell is traveling faster than the wind and in the same direction, resulting in a wave-induced upward flux of momentum. Typically this occurs at wind speeds less than $1.5-2 \mathrm{~m} \mathrm{~s}^{-1}$ (Grachev and Fairall 2001). Therefore, all measurements at wind speeds below $1.5 \mathrm{~m} \mathrm{~s}^{-1}$ were not used for analysis. Comparisons of both methods by, for example, Fairall et al. (2003), showed a very close agreement between ID and the covariance method. The study of Grachev et al. (2011) came out with the result that both methods agree within their uncertainties, even in coastal areas except for very low wind speeds, while Drennam et al. (1999) found considerable deviations between eddy correlation and the inertial dissipation method during rough seas. However, the latter is only of small interest for real measurements on ships, since during rough seas the humidity measurements are strongly hampered by sea spray.

The ID fluxes were computed from 18-min (wind components and sonic temperature) and 13-min (absolute humidity) time series within a 30-min section. Fluxes were calculated normal to the plane spanned by the horizontal wind components. The time series are filtered using a Hamming window. The ID flux techniques are based on the turbulent kinetic energy $e$ budget as follows (e.g., Edson and Fairall 1998):

$-\overline{u w} \frac{\partial \bar{U}}{\partial z}-\overline{v w} \frac{\partial \bar{V}}{\partial z}+\frac{g}{\bar{\theta}_{v}} \overline{w \theta_{v}}-\frac{1}{\rho} \frac{\partial \overline{w p}}{\partial z}-\frac{\partial \overline{w e}}{\partial z}-\varepsilon=0$,

where $u, v$, and $w$ are the fluctuations of the wind components; $\bar{U}$ and $\bar{V}$ are the mean horizontal wind components; $z$ is the height; $\theta_{v}$ is the virtual potential temperature; $\rho$ is the air density; $p$ denotes pressure fluctuations; and $\varepsilon$ is the dissipation of turbulent kinetic energy into heat. A bar indicates temporal averaging. The first two terms represent the production of mechanical turbulence by shear, the third term is the production by convection, and the fourth and fifth terms act to redistribute turbulent kinetic energy through pressure and energy transport in the atmospheric boundary layer.

After a normalization using appropriate scaling parameters $\kappa z / u_{*}^{2}$, where $\kappa$ is the Kármán constant and $u *$ is the friction velocity, the turbulent kinetic energy budget can be written in its nondimensional form according to Large and Pond (1982). By introducing the dimensionless shear $\phi_{m}$; stability $\zeta=z / L$, where $L$ is the Obukhov stability length (Obukhov 1946); and the velocity, temperature, and humidity scales $u_{*}, t_{*}$, and $q_{*}$, respectively (e.g., Edson and Fairall 1998); the equation can be solved for $u *$ (see the appendix).

Dissipation rates are computed from the measured one-dimensional variance spectra. In the inertial subrange of isotropic turbulence, the one-dimensional variance spectrum $\Phi_{u}$ of the wind component $u$ can be expressed as a function of the wavenumber:

$$
\Phi_{u}(k)=\alpha_{u} \varepsilon^{2 / 3} k^{-5 / 3},
$$

where $k$ is the wavenumber and $\alpha_{u}$ is the Kolmogorov constant. The Kolmogorov constant $\alpha_{u}=0.52$ was taken from Högström (1996). Using Taylor's hypothesis, these spectra are related to the frequency spectra $S_{u}$. Inaccuracies in Taylor's hypothesis are corrected according to Wyngaard and Clifford (1977). 


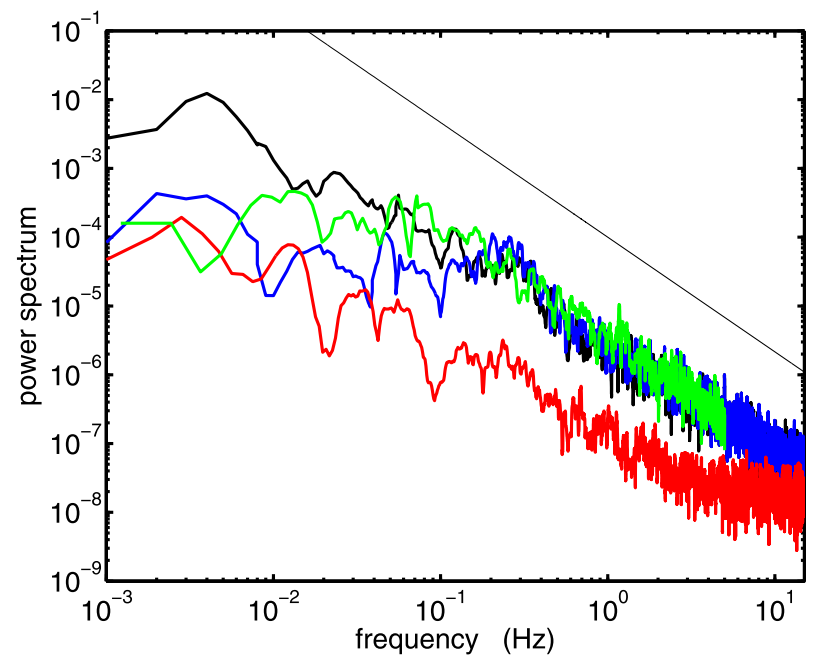

FIG. 1. Typical raw spectra of the $u$ component (black), $w$ component (blue), temperature (red), and specific humidity (green). The $-5 / 3$ law is indicated by the thin black line.

Neglecting the pressure term and transport term according to, for example, Large and Pond (1982), the friction velocity can be computed from

$$
u_{*}=\left(\frac{2 \pi \kappa z}{\bar{U}}\right)^{2 / 3} \frac{S_{u}(f) f^{5 / 3}}{\alpha_{u}(2 \pi)^{2 / 3}}\left[\phi_{m}(\zeta)-\zeta\right]
$$

where $f$ is the frequency. The inertial dissipation method for scalar fluxes is based on the budget of the scalar variances (Large and Pond 1982), which simplify under horizontal homogeneous and stationary conditions to

$$
\begin{aligned}
& \overline{w \theta} \frac{\partial \bar{\theta}}{\partial z}+0.5 \frac{\partial \overline{w \theta^{2}}}{\partial z}+N_{\theta}=0 \quad \text { and } \\
& \overline{w q} \frac{\partial \bar{q}}{\partial z}+0.5 \frac{\partial \overline{w q^{2}}}{\partial z}+N_{q}=0 .
\end{aligned}
$$

Neglecting the vertical divergence term and substituting the temperature scale $t_{*}$ and the humidity scale $q_{*}$, the flux profile relationships (Large and Pond 1982) simplify to

$$
\begin{aligned}
& \overline{w \theta}=\left[\frac{\kappa z u_{*} N_{\theta}}{\phi_{\theta}(\zeta)}\right]^{1 / 2} \text { and } \\
& \overline{w q}=\left[\frac{\kappa z u_{*} N_{q}}{\phi_{q}(\zeta)}\right]^{1 / 2},
\end{aligned}
$$

where $N_{\theta}$ and $N_{q}$ are the turbulent dissipation rates for half the temperature and humidity variances and $\phi_{\theta}$ and

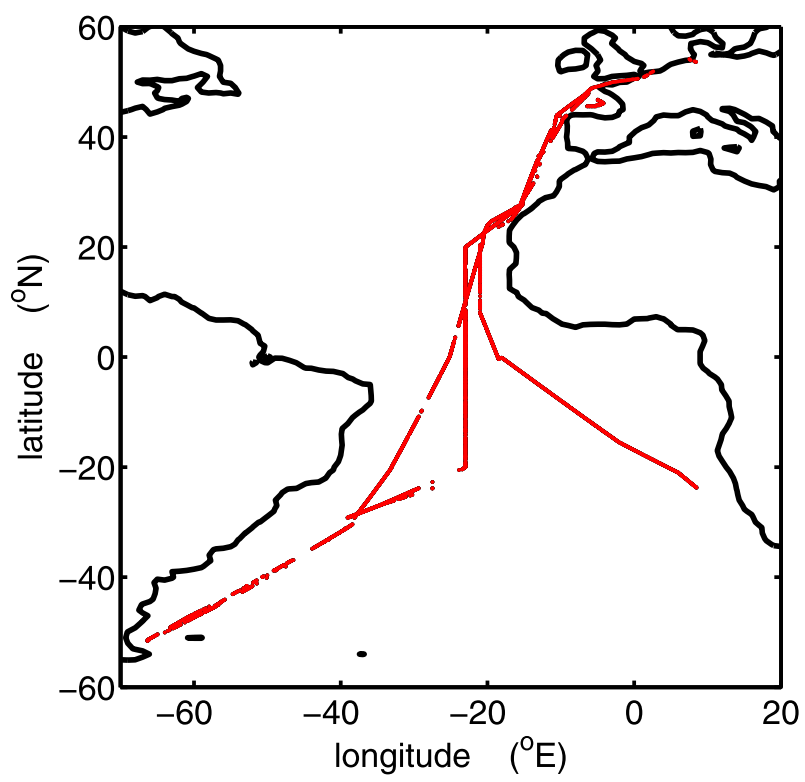

FIG. 2. Positions of the turbulence measurements on board the R/V Polarstern.

$\phi_{q}$ are universal functions of stability $\zeta$. The terms $N_{\theta}$ and $N_{q}$ can be inferred from spectral energy densities $S_{\theta}$ and $S_{q}$ in the inertial subrange according to

$$
\begin{aligned}
& S_{\theta}(f)=\beta_{\theta}^{\prime} \varepsilon^{-1 / 3} N_{\theta}\left(\frac{2 \pi}{\bar{U}}\right)^{-2 / 3} f^{-5 / 3} \text { and } \\
& S_{q}(f)=\beta_{q}^{\prime} \varepsilon^{-1 / 3} N_{q}\left(\frac{2 \pi}{\bar{U}}\right)^{-2 / 3} f^{-5 / 3},
\end{aligned}
$$

where $\beta_{\theta}^{\prime}$ and $\beta_{q}^{\prime}$ are set to 0.8 (Large and Pond 1982).

The profile functions are adopted from Beljaars and Holtslag (1991) and Dyer (1974). In the case of free convection these were replaced according to Grachev et al. (2000).

Because the Obukhov length depends on friction velocity and heat fluxes, a modified bulk scheme [LiuKatsaros-Businger (LKB) scheme (Liu et al. 1979)] following Liu and Blanc (1984), based on the algorithm from Liu et al. (1979), was used as a first guess of the turbulent fluxes using bulk coefficients according to Large and Pond (1982). A fixed value of the Charnock parameter in the LKB scheme, as suggested in the study by Taylor and Yelland (2000), was replaced by a wind speed-dependent one according to Fairall et al. (2003). Then the turbulent parameters were iteratively derived by making use of the measured fluxes until convergence in $u_{*}$ was reached. Temperatures taken from the sonic anemometer are close to the virtual temperature (Kaimal and Gaynor 1991); the measured heat fluxes are corrected 


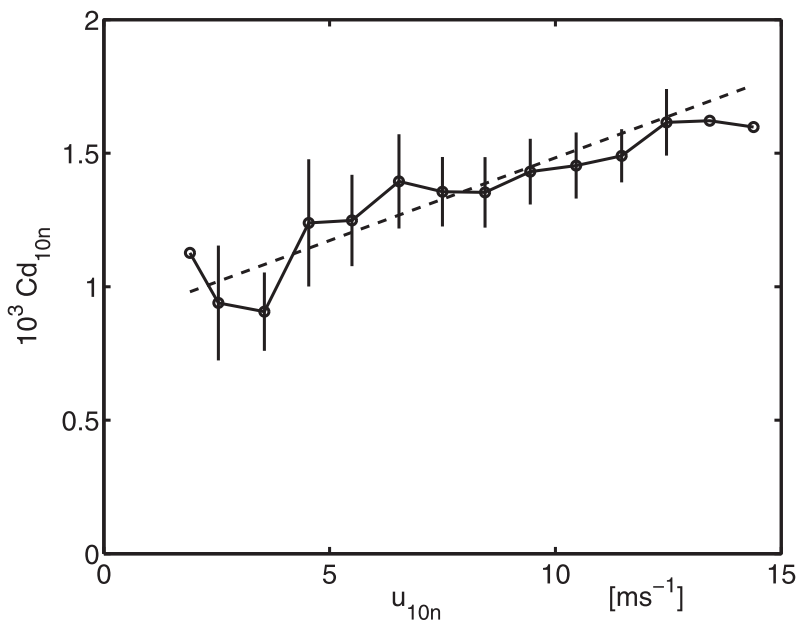

FIG. 3. Drag coefficient Cd, reduced to 10-m height and neutral stability, as a function of wind speed. Values are computed in $1 \mathrm{~m} \mathrm{~s}^{-1}$ wind speed bins; vertical bars give the standard deviation if a minimum of 30 values is available for a wind speed bin.

according to Dupuis et al. (1997). More details, for example, about implemented profile functions are given in the appendix.

To ensure that spectral densities are in the inertial subrange, it was verified that spectra are proportional to $f^{5 / 3}$. Time series with deviations larger than $10 \%$ from the $-5 / 3$ law and a ratio of the longitudinal to lateral spectral densities of less than 1 indicate deviations from local isotropic conditions and were rejected. The remaining deviations from local isotropy were corrected according to Wucknitz (1978). Typical raw spectra are depicted in Fig. 1. Spectral information was taken from 1 to $2 \mathrm{~Hz}$ for humidity data and from 2 to $4 \mathrm{~Hz}$ for wind components and sonic temperature.

\section{Results}

\section{a. Bulk transfer coefficients}

At least 3000 time series could be analyzed to derive bulk transfer coefficients for the momentum and sensible and latent heat fluxes. The positions of the measurements are given in Fig. 2. In general, distances to the coast are farther than $200 \mathrm{n} \mathrm{mi}(\sim 370 \mathrm{~km})$. Only a few measurements exist in which distances to the coast are less than $20 \mathrm{n}$ mi. As mentioned above, skin temperature has been estimated using an algorithm from Hasse (1970). Bulk transfer coefficients were reduced to neutral stability and 10-m height using the modified LKB scheme. The resulting bulk transfer coefficients, representing 1-h observation averages were computed in $1 \mathrm{~m} \mathrm{~s}^{-1} 10-\mathrm{m}$ neutral wind speed bins. These results are shown in Figs. 3-5. Linear fits to the hourly bulk transfer coefficients on 10-m neutral wind speed gave

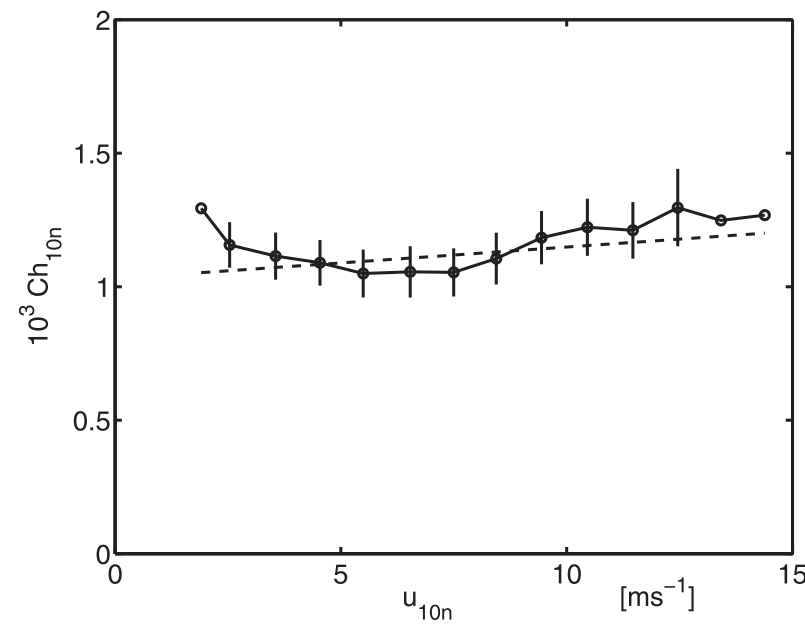

FIG. 4. As in Fig. 3, but for bulk transfer coefficient for sensible heat $\mathrm{Ch}$.

$$
\begin{aligned}
& \mathrm{Cd}_{10 \mathrm{n}}=\left(0.86+0.062 U_{10 \mathrm{n}}\right) \times 10^{-3}, \\
& \mathrm{Ch}_{10 \mathrm{n}}=\left(1.03+0.012 U_{10 \mathrm{n}}\right) \times 10^{-3}, \text { and } \\
& \mathrm{Ce}_{10 \mathrm{n}}=\left(1.06+0.005 U_{10 \mathrm{n}}\right) \times 10^{-3} .
\end{aligned}
$$

While the bulk transfer coefficient of momentum $\mathrm{Cd}_{10 \mathrm{n}}$ increases strongly with wind speed, the Stanton $\mathrm{Ch}_{10 \mathrm{n}}$ and Dalton $\mathrm{Ce}_{10 n}$ numbers only slightly increase with wind speed. These results are similar to those of other studies (e.g., Fairall et al. 2003). The uncertainty in the coefficients is given in terms of standard deviation by the vertical bars in Figs. 3-5, if a minimum of 30 observations are available in a wind speed bin. The uncertainties are also comparable to those given by Fairall et al. (2003).

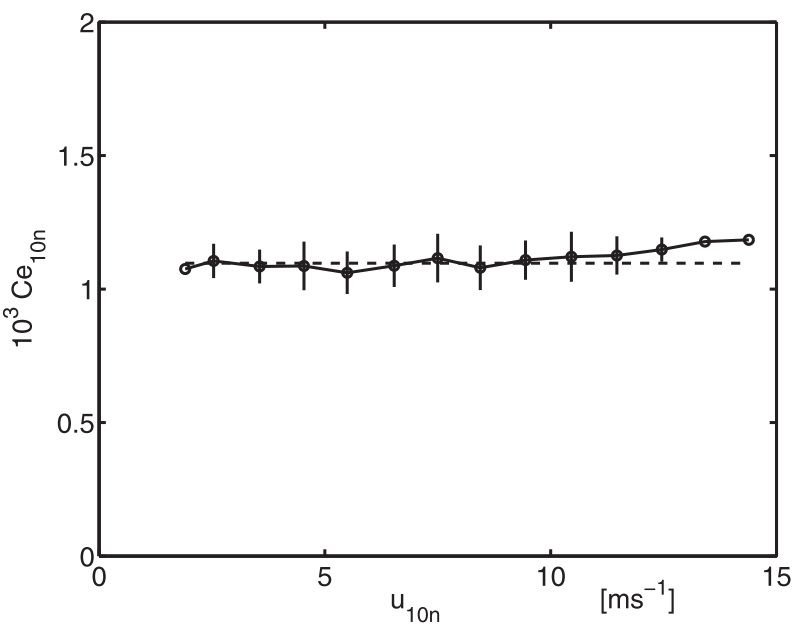

FIG. 5. As in Fig. 3, but for bulk transfer coefficient for latent heat $\mathrm{Ce}$. 


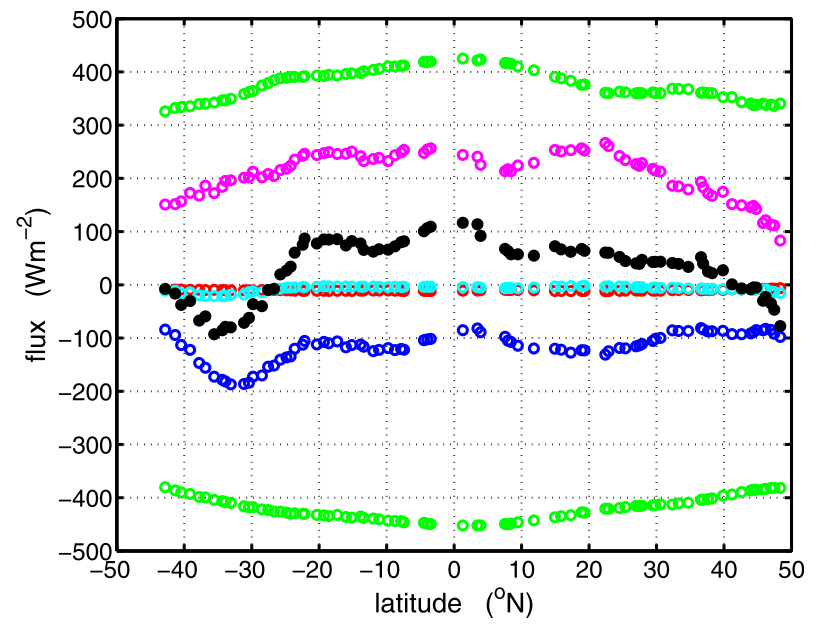

FIG. 6. Energy fluxes and the total energy budget at the air-sea interface as a function of latitude for all Atlantic transects of the R/V Polarstern (magenta: downward solar radiation, red: reflected solar radiation, top green: downward longwave radiation, bottom green: upward longwave radiation, blue: latent heat flux, cyan: sensible heat flux, and black: total energy budget). Heat fluxes were computed from 1-hourly averages of the onboard data, downward radiation fluxes were directly measured, reflected solar radiation fluxes were estimated according to Taylor et al. (1996), and upward longwave radiation was estimated according to the Stefan-Boltzmann law, assuming an emissivity of 0.97 from the skin temperature. The skin temperature was computed iteratively from the bulk water temperature given by the onboard data and estimated energy fluxes following the formulation from Hasse (1970).

\section{b. Energy budget at the sea surface}

The bulk transfer coefficients can be applied to the ship's meteorological data to derive the heat and energy fluxes at the sea surface. Hence, 1-h means are computed from the ship's data, which have a temporal resolution of $1 \mathrm{~min}$. The downward solar radiation is measured as well as the downward longwave radiation at rates lying between $2 \mathrm{~s}$ and $1 \mathrm{~min}$. The reflected solar radiation was computed according to an algorithm described in Taylor et al. (1996). The upward longwave radiation was estimated from the skin temperature according to the Stefan-Boltzmann law using an emissivity of 0.97 [Eq. (2)]. As mentioned above, the skin temperature was computed following Hasse (1970) from the intake temperature, taking measured radiation fluxes and heat fluxes into account. The heat fluxes, upward longwave radiation, and $T_{s}$ were iteratively estimated until convergence in $T_{s}$ was reached. Figure 6 depicts daily averaged fluxes averaged over $5^{\circ}$ latitude sections for all R/V Polarstern cruises. Although it is far away from a climatological mean, typical variations are shown, especially in the radiation fluxes and latent heat fluxes. As expected, the mean total flux is positive, but there are

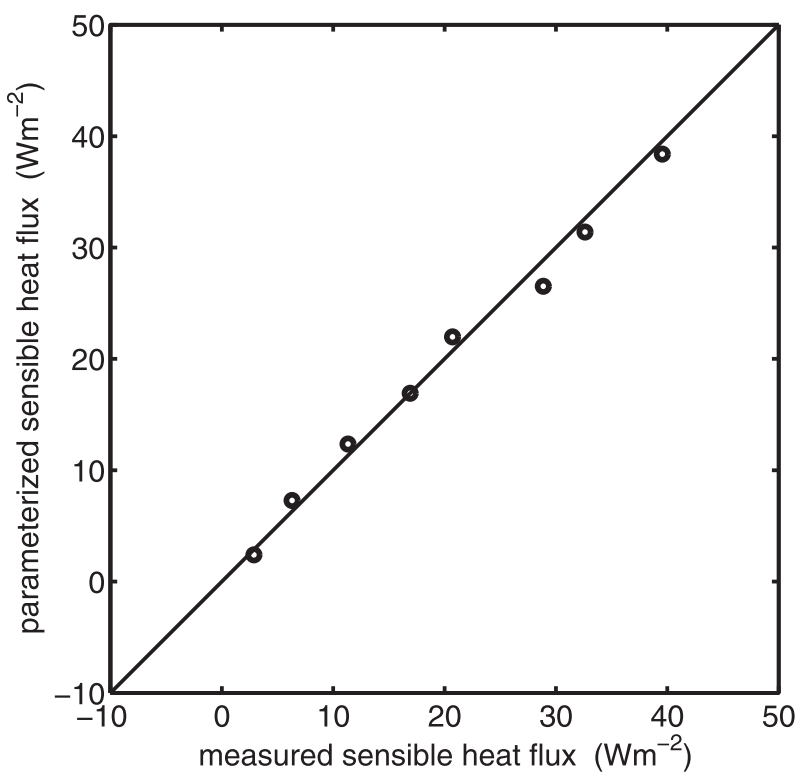

FIG. 7. Comparison of measured and parameterized sensible heat fluxes derived by the GEOMAR bulk flux algorithm, averaged over bins of $5 \mathrm{~W} \mathrm{~m}^{-2}$ of measured fluxes. The solid line gives the $1: 1$ ratio.

also areas where it is negative, indicating energy loss of the ocean. Comparing all fluxes, it is obvious that the variations in the energy budget are mainly due to insolation and evaporation. This is reflected by a correlation of 0.95 between the solar radiation budget and the total energy flux and a correlation of -0.91 between the latent heat flux and the total energy budget minus the shortwave radiation budget. The sensible heat flux was, in general, small during the Atlantic transects.

\section{c. Comparison of parameterization and measurements}

Figures 7 and 8 depict a comparison between the mean values of measured and parameterized sensible and latent heat fluxes derived by the GEOMAR bulk flux algorithm. The mean values were estimated for bins of $5 \mathrm{~W} \mathrm{~m}^{-2}$ width for measured sensible heat fluxes and $50 \mathrm{~W} \mathrm{~m}^{-2}$ for measured latent heat fluxes. The overall agreement between the mean values is very good. This is also reflected in the correlation coefficients between the single values of 0.89 for sensible and 0.95 for latent heat fluxes. Standard deviations of the difference between single measurements and parameterizations are 3.0 and $20.2 \mathrm{~W} \mathrm{~m}^{-2}$ for sensible and latent heat fluxes, with biases of 0 and $-3.9 \mathrm{~W} \mathrm{~m}^{-2}$, respectively.

\section{d. Comparison to COARE3.0 bulk flux algorithm}

Over 3000 hourly means of ship data were used as input in our parameterization scheme and in the available 


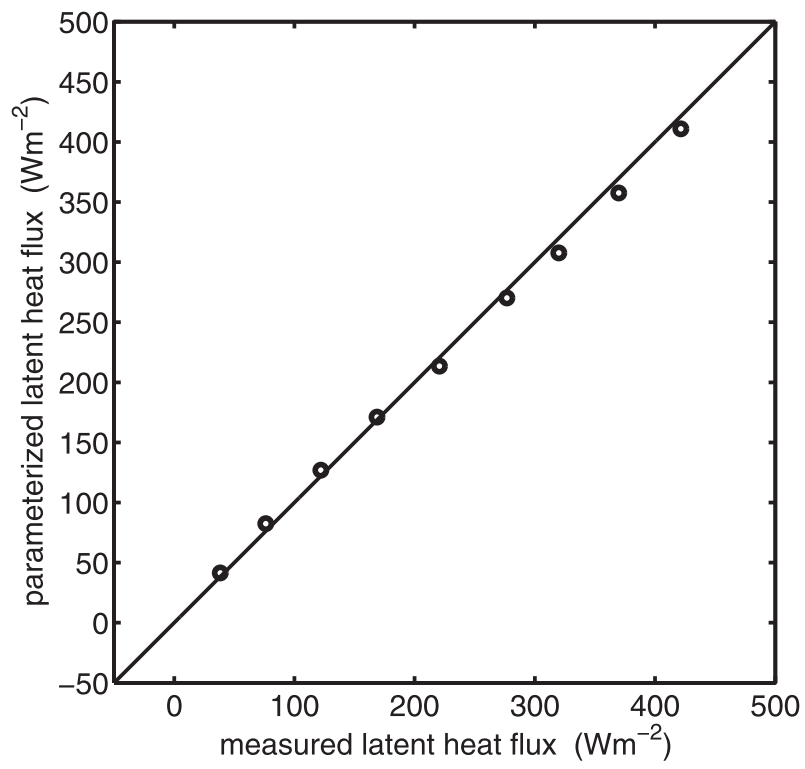

FIG. 8. Comparison of measured and parameterized latent heat fluxes, averaged over bins of $50 \mathrm{~W} \mathrm{~m}^{-2}$ of measured fluxes. The solid line gives the $1: 1$ ratio.

COARE3.0 bulk flux model (MatLab version; Fairall 2011) with the precipitation set to zero.

Figures 9-11 show comparisons of the sensible and latent heat flux and the total energy budget, and Table 2

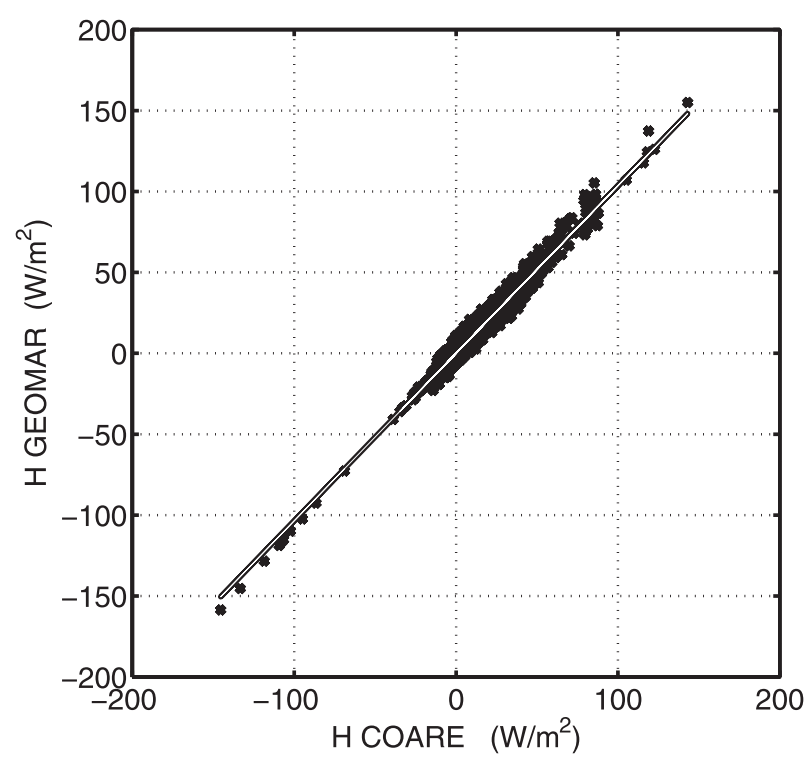

FIG. 9. Comparison of parameterized sensible heat fluxes. COARE indicates parameterizations by applying the Matlab routines of Fairall (2011) on the data; GEOMAR indicates our own parameterizations. Estimated fluxes are computed from 1-h averages of the ship's meteorological data. The solid line gives the results of a linear regression. The standard deviation between both parameterizations is $3.9 \mathrm{~W} \mathrm{~m}^{-2}$.

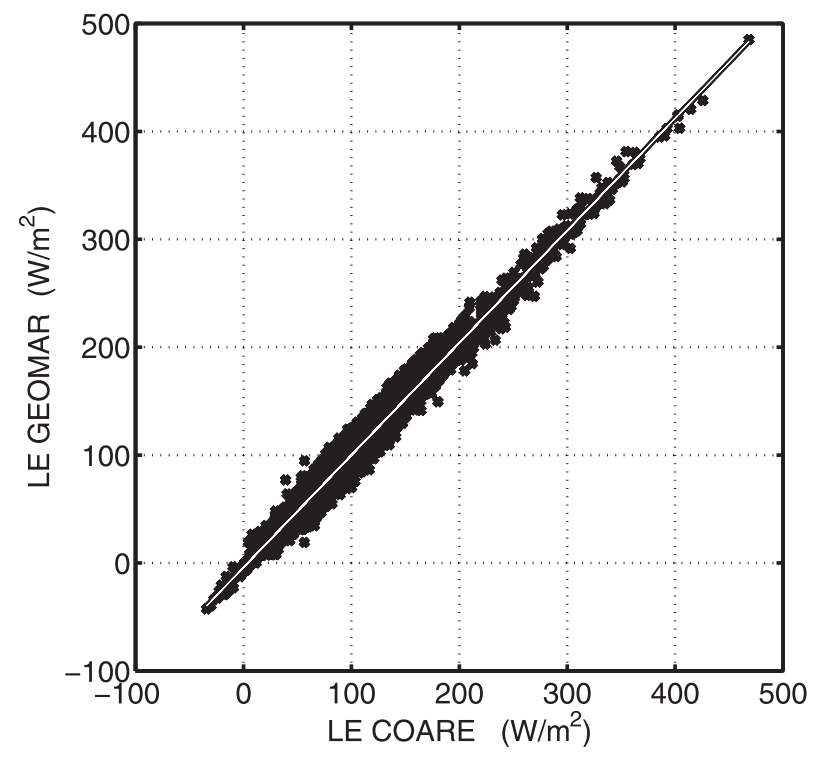

FIG. 10. As in Fig. 9, but for parameterized latent heat fluxes. The standard deviation between both parameterizations is $11 \mathrm{~W} \mathrm{~m}^{-2}$.

lists the statistical parameters. The correlations between the two approaches are 0.975 and higher, with biases on the order of $2 \mathrm{~W} \mathrm{~m}^{-2}$ and standard deviations smaller than $13 \mathrm{~W} \mathrm{~m}^{-2}$ even for the total energy flux (Table 2). The regression coefficients from the linear fits between both parameterizations are also close to 1 . Thus, in general, the agreement is excellent between both parameterizations.

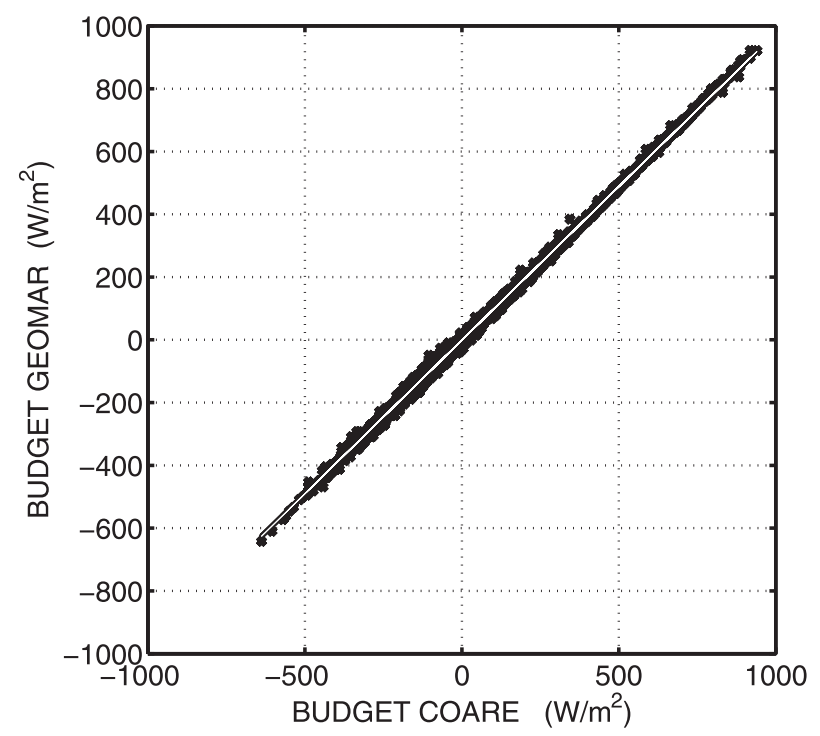

FIG. 11. As in Fig. 9, but for parameterized total energy budgets. The standard deviation between both parameterizations is $12.4 \mathrm{~W} \mathrm{~m}^{-2}$. 
TABLE 2. Statistical parameters of the comparison between parameterized fluxes of this study with parameterized fluxes applying the COARE3.0 bulk flux parameterization scheme (Fairall et al. 2003) on 1-h averages of the ship's meteorological data. The index $c$ indicates COARE3.0.

\begin{tabular}{lcccc}
\hline \hline & Sensible heat flux $H$ & Latent heat flux LE & $\begin{array}{c}\text { Upward longwave } \\
\text { radiation } F_{\text {lw }}\end{array}$ & $\begin{array}{c}\text { Total energy } \\
\text { budget } F_{\text {tot }}\end{array}$ \\
\hline Correlation coef & 0.975 & 0.99 & 0.997 & 0.999 \\
Regression $\left(\mathrm{W} \mathrm{m}^{-2}\right)$ & $1.04 H_{c}+0.05$ & $1.04 \mathrm{LE}_{c}-4.1$ & $1.04 F_{\text {lwc }}+0.03$ & $0.98 F_{\text {totc }}-0.95$ \\
Bias $\left(\mathrm{W} \mathrm{m}^{-2}\right)$ & -0.3 & -0.4 & +1.9 & +1.6 \\
Std dev $\left(\mathrm{W} \mathrm{m}^{-2}\right)$ & 3.9 & 10.8 & 2.3 & 12.2 \\
\hline
\end{tabular}

\section{Summary}

Turbulence measurements derived from onboard measurements from the R/V Polarstern have been analyzed with respect to bulk coefficients. The estimated coefficients are comparable to the results from other studies like Fairall et al. (2003). Comparisons of parameterized fluxes based on our results to parameterized fluxes applying the widely used COARE3.0 bulk flux algorithm to the ship's meteorological measurements show an excellent agreement. That also answers the question of whether deviations between different datasets compared to bulk flux data are caused by uncertainties in the bulk parameterization scheme. The results of this study clearly show that biases on the order of $20 \%$ (e.g., Yu et al. 2008) cannot result from uncertainties in the bulk parameterization scheme. Moreover the results suggest that the COARE3.0 bulk flux algorithm gives accurate estimates of the heat fluxes and is a valuable tool for validation studies. However, the statistical uncertainties between both parameterizations and parameterization and measurement in terms of bias and standard deviation are an important source of information for validating different datasets, as was done, for example, in the frame of the Objectively Analyzed Air-Sea Fluxes (OAFlux) project ( $\mathrm{Yu}$ et al. 2008).

Comparisons of heat fluxes derived directly from turbulence measurements and our parameterizations showed that the data can also be used for direct comparisons to model data like the European Centre for Medium-Range Weather Forecasts (ECMWF) Interim Re-Analysis (ERA-Interim) data (Dee et al. 2011) or satellite-derived datasets like the Hamburg Ocean Atmosphere Parameters and Fluxes from Satellite Data (HOAPS; Andersson et al. 2010).

In addition to the applicability of these data as a validation tool, they are necessary prerequisites for accurate ocean modeling. The knowledge of evaporation also enables us to estimate freshwater budgets when accurate precipitation measurements are available. Meanwhile, an optical disdrometer for measuring precipitation has been mounted on the R/V Polarstern and other research vessels by Hamburg University in order to fill in this data gap.

Acknowledgments. We kindly acknowledge the support from the Leibniz Association, who funded this study. We thank also the Alfred Wegener Institute for Polar and Marine Research (AWI) for providing the opportunity to join several research cruises across the Atlantic Ocean on the R/V Polarstern. Especially many thanks are given to the masters of the $\mathrm{R} / \mathrm{V}$ Polarstern and their crews for their support on the expeditions ANT-XXIV/4, ANT-XXV/5, ANT-XXVI/1, and ANT-XXVII/1.

\section{APPENDIX}

\section{Details of the Flux-Processing Method}

The Monin-Obukhov similarity theory scaling parameters are friction velocity $u_{*}$, temperature scale $t_{*}$, and humidity scale $q_{*}$, which are defined as (Large and Pond 1982)

$$
\begin{aligned}
& u_{*}=\sqrt{|\overline{u w}|}, \\
& t_{*}=-\frac{\overline{w \theta}}{\kappa u_{*}}, \text { and } \\
& q_{*}=-\frac{\overline{w q}}{\kappa u_{*}} .
\end{aligned}
$$

The Monin-Obukhov stability parameter is given by

$$
\zeta=\frac{z}{L}=-\frac{\kappa g z}{T} \frac{(\overline{w \theta}+0.61 T \overline{w q})}{(\overline{-w u})^{3 / 2}},
$$

(Fairall et al. 2003) where $T$ is the temperature, $g$ is the acceleration due to gravity, and $z$ is the height of the measurements.

The definition of the velocity roughness length $z_{0}$ follows the COARE3.0 bulk flux algorithm (Fairall et al. 2003): 


$$
z_{0}=\frac{\alpha u_{*}^{2}}{g}+\frac{0.11 \nu}{u_{*}},
$$

where $\nu$ is the kinematic viscosity and $\alpha$ is the Charnock constant, which increases linearly from 0.011 at a $10-\mathrm{m}$ neutral wind speed of $10 \mathrm{~m} \mathrm{~s}^{-1}$ to 0.018 at $18 \mathrm{~m} \mathrm{~s}^{-1}$; below and beyond these wind speeds it remains constant. Scalar roughness lengths were also adopted from Fairall et al. (2003)

$$
z_{0 q}=z_{0 \mathrm{t}}=\min \left(1.1 \times 10^{-4}, 5.5 \times 10^{-5} R_{r}^{-0.6}\right),
$$

where $R_{r}$ is the roughness Reynolds number.

The profile functions are adopted from Beljaars and Holtslag (1991) and Dyer (1974). Under unstable conditions, they are

$$
\begin{aligned}
x & =(1-16 \zeta)^{1 / 4}, \\
\psi_{u k} & =2 \log [(1+x) / 2]+\log \left[\left(1+x^{2}\right) / 2\right]-2 \operatorname{atan}(x)+\pi / 2,
\end{aligned}
$$

and

$$
\begin{aligned}
x & =(1-16 \zeta)^{1 / 2}, \\
\psi_{t k} & =\psi_{q k}=2 \log [(1+x) / 2],
\end{aligned}
$$

where the subscript $k$ denotes the Kansas form.

In the case of free convection, these were replaced according to Grachev et al. (2000) by

$$
\begin{aligned}
y= & (1-10.15 \zeta)^{1 / 3}, \\
\psi_{u c}= & 1.5 \log \left[\left(1+y+y^{2}\right) / 3\right] \\
& -\sqrt{3} \operatorname{atan}[(1+2 y) / \sqrt{3}]+\pi / \sqrt{3},
\end{aligned}
$$

and

$$
\begin{aligned}
y= & (1-34.15 \zeta)^{1 / 3} \\
\psi_{t c}= & \psi_{q c}=1.5 \log \left[\left(1+y+y^{2}\right) / 3\right] \\
& -\sqrt{3} \operatorname{atan}[(1+2 y) / \sqrt{3}]+\pi / \sqrt{3}
\end{aligned}
$$

where the subscript $c$ indicates convective.

According to Fairall et al. (2003), unstable and convective profile functions are weighted by

$$
\psi_{u}=\frac{(1-f) \psi_{u k}}{f \psi_{u c}} \text { and }
$$

$$
\psi_{t}=\psi_{q}=\frac{(1-f) \psi_{t k}}{f \psi_{t c}}
$$

with $f=\zeta^{2} /\left(1+\zeta^{2}\right)$.

Under stable stratification, the profile functions are given by

$$
\begin{aligned}
& \psi_{u}=-\left[(1+1 \times \zeta)+\frac{2}{3} \frac{\zeta-14.28}{\exp (c)}+8.525\right] \text { and } \\
& \psi_{t}=\psi_{q}=-\left[(1+1 \times \zeta)^{1.5}+\frac{2}{3} \frac{\zeta-14.28}{\exp (c)}+8.525\right]
\end{aligned}
$$

where $c=\min (50,0.35 \zeta)$ (Fairall et al. 2003).

\section{REFERENCES}

Andersson, A., K. Fennig, C. Klepp, S. Bakan, H. Graß1, and J. Schulz, 2010: The Hamburg Ocean Atmosphere Parameters and Fluxes from Satellite Data-HOAPS-3. Earth Syst. Sci. Data, 2, 215-234, doi:10.5194/essd-2-215-2010.

Beljaars, A. C. M., and A. A. M. Holtslag, 1991: Flux parameterization over land surfaces for atmospheric models. J. Appl. Meteor., 30, 327-341.

Berry, D. I., B. I. Moat, and M. J. Yelland, 2001: Airflow distortion at instrument sites on the FS Polarstern. Southampton Oceanography Centre Internal Doc. 69, 39 pp. [Available online at http://www.noc.soton.ac.uk/JRD/MET/PDF/cfd_ polarstern_DOC69.pdf.]

Bumke, K., 2011: The expedition of the research vessel "Polarstern" to the Antarctic in 2010 (ANT-XXVII/1). Alfred-WegenerInstitut Berichte zur Polar- und Meeresforschung (Rep. on Polar and Marine Research) 628, 87 pp. [Available online at http://hdl.handle.net/10013/epic.37742.]

Dee, D. P., and Coauthors, 2011: The ERA-Interim reanalysis: Configuration and performance of the data assimilation system. Quart. J. Roy. Meteor. Soc., 137, 553-597, doi:10.1002/ qj. 828 .

Drennam, W. M., K. K. Kahma, and M. A. Donelan, 1999: On momentum flux and velocity spectra over waves. Bound. Layer Meteor., 92, 489-515.

Dupuis, H., P. K. Taylor, A. Weill, and K. Katsaros, 1997: Inertial dissipation method applied to derive turbulent fluxes over the ocean during the surface of the ocean. J. Geophys. Res., 102 (C9), 21115-21129.

Dyer, A. J., 1974: A review of flux profile relationships. Bound.Layer Meteor., 7, 363-372.

Edson, J. B., and C. W. Fairall, 1998: Similarity relationships in the marine atmospheric surface layer for terms in the TKE and scalar variance budgets. J. Atmos. Sci., 55, 2311-2328.

,-- , P. G. Mestayer, and S. E. Larsen, 1991: A study of the inertial-dissipation method for computing air-sea fluxes. J. Geophys. Res., 96 (C6), 10 689-10 711.

El Naggar, S., and E. Fahrbach, 2010: Handbuch FS Polarstern: Ein Leitfaden zur Planung und Durchführung von Expeditionen mit FS Polarstern. Alfred-Wegener-Institut Rep., 89 pp.

— and A. E. Macke, 2010: The expedition of the research vessel "Polarstern" to the Antarctic in 2009 (ANT-XXVI/1). AlfredWegener-Institut Berichte zur Polar- und Meeresforschung (Rep. on Polar and Marine Research) 614, 75 pp. 
Fairall, C. W., 2011: Matlab program codes cor3_0af.m and cor3_0ah.m. [Available online at ftp://ftp1.esrl.noaa.gov/ users/cfairall/bulkalg/cor3_0/matlab3_0/.]

— turbulent fluxes at the air-ocean interface. Bound.-Layer Meteor., 34, 287-301.

— , E. F. Bradley, J. E. Hare, A. A. Grachev, and J. B. Edson, 2003: Bulk parameterization of air-sea fluxes: Updates and verification for the COARE algorithm. J. Climate, 16, 571-591.

Grachev, A. A., and C. W. Fairall, 2001: Upward momentum transfer in the marine boundary layer. J. Phys. Oceanogr., 31, 1698-1711.

,-- , and E. F. Bradley, 2000: Convective profile constants revisited. Bound.-Layer Meteor., 94, 495-515.

— L. Lariteau, C. W. Fairall, J. E. Hare, D. Helmig, J. Hueber, and E. K. Lang, 2011: Turbulent fluxes and transfer of trace gases from ship-based measurements during TexAQS 2006. J. Geophys. Res., 116, D13110, doi:10.1029/2010JD015502.

Hasse, L., 1970: The sea surface temperature deviation and the heat flow at the sea-air interface. Bound.-Layer Meteor., 1 , 368-379, doi:10.1007/BF02186037.

Högström, U., 1996: Review of some basic characteristics of the atmospheric surface layer. Bound.-Layer Meteor., 78, 215-246.

Kaimal, J. C., and J. E. Gaynor, 1991: Another look at sonic thermometry. Bound.-Layer Meteor., 56, 401-410.

Kalisch, J., and A. Macke, 2012: Radiative budget and cloud radiative effect over the Atlantic from ship-based observations. Atmos. Meas. Tech., 5, 2391-2401, doi:10.5194/amt-5-2391-2012.

Large, W. G., and S. Pond, 1982: Sensible and latent heat flux measurements over the ocean. J. Phys. Oceanogr., 12, 464-482.

_- and S. G. Yeager, 2009: The global climatology of an interannually varying air-sea flux data set. Climate Dyn., 33, 341-364.

Liu, W. T., and T. V. Blanc, 1984: The Liu, Katsaros, and Businger (1979) bulk atmospheric flux computational iteration program in FORTRAN and BASIC. Naval Research Laboratory Memo. Rep. 5291, 16 pp.

— K. K. Katsaros, and J. A. Businger, 1979: Bulk parameterizations of air-sea exchanges of heat and water vapor including the molecular constraints at the interface. J. Atmos. Sci., 36, 1722-1735.

Macke, A. E., 2009: The expedition of the research vessel "Polarstern" to the Antarctic in 2008 (ANT-XXIV/4). Alfred-Wegener-Institut Berichte zur Polar- und Meeresforschung (Rep. on Polar and Marine Research) 591, 65 pp.
_ J. Kalisch, Y. Zoll, and K. Bumke, 2010: Radiative effects of the cloudy atmosphere from ground and satellite based observations. EPJ Web Conf., 59, 83-94.

Muraleedharan, P. M., and T. Pankajakehan, 2008: How consistent is the satellite derived SST-LHF relationship in comparison with observed values? Int. J. Remote Sens., 29, 4207-4217.

Obukhov, A. M., 1946: Turbulence in an atmosphere with a nonuniform temperature. Tr. Inst. Teor. Geofiz. Akad. Nauk. SSSR, 1, 95-115.

Ohmura, A., and Coauthors, 1998: Baseline Surface Radiation Network (BSRN/WCRP): New precision radiometry for climate research. Bull. Amer. Meteor. Soc., 79, 2115-2136.

Rutledge, C. K., G. L. Schuster, T. P. Charlock, F. M. Denn, W. L. Smith Jr., B. E. Fabbri, J. J. Madigajn Jr., and R. J. Knapp, 2006: Offshore radiation observations for climate research at the CERES ocean validation experiment: A new "laboratory" for retrieval algorithm testing. Bull. Amer. Meteor. Soc., 87, 1211-1222.

Schmitt, R. W., 1999: The ocean's response to the freshwater cycle. Global Energy and Water Cycles, K. Browning and R. Gurney, Eds., Cambridge University Press, 144-154.

Taylor, P. K., and M. A. Yelland, 2000: On the apparent "imbalance" term in the turbulent kinetic energy budget. J. Atmos. Oceanic Technol., 17, 82-89.

_ J. M. Edwards, M. D. Glew, P. Hignett, and A. Slingo, 1996: Studies with a flexible new radiation code. II: Comparisons with aircraft shortwave observations. Quart. J. Roy. Meteor. Soc., 122, 839-861.

Wucknitz, J., 1978: The influence of anisotropy on stress estimation by the indirect dissipation method. Bound-Layer Meteor., 17, $119-131$.

Wyngaard, J. C., and S. F. Clifford, 1977: Taylor's hypothesis and high frequency turbulence spectra. J. Atmos. Sci., 34, 922-929.

Yu, L., X. Jin, and R. A. Weller, 2008: Multidecade global flux datasets from objectively analyzed air-sea fluxes (OAFlux) project: Latent and sensible heat fluxes, ocean evaporation, and related surface meteorological variables. Woods Hole Oceanographic Institution OAFlux Project Tech. Rep. OA2008-01, 64 pp.

Zenk, W., and S. El Naggar, 2010: The expedition of the research vessel "Polarstern" to the Antarctic in 2009 (ANT-XXV/5). AlfredWegener-Institut Berichte zur Polar- und Meeresforschung (Rep. on Polar and Marine Research) 603, 59 pp. 